\title{
Analysis of Hematologic Parameters and Serum Bilirubin Levels in Complicated and Uncomplicated Acute Appendicitis Patients
}

\author{
Rini Rahman ${ }^{1}$, Ani Kartini ${ }^{2,3}$, Yuyun Widaningsih ${ }^{2}$, Agus Alim Abdullah ${ }^{2,3}$ \\ ${ }^{1}$ Resident of Clinical Pathology Program, Faculty of Medicine, Hasanuddin University/Dr. WahidinSudirohusodo Hospital, Makassar, \\ Indonesia.E-mail: rinirahmanmd@gmail.com \\ ${ }^{2}$ Department of Clinical Pathology, Faculty of Medicine, Hasanuddin University/Dr. WahidinSudirohusodo Hospital, Makassar, Indonesia \\ ${ }^{3}$ Department of Clinical Pathology, Faculty of Medicine, Hasanuddin University/Dr. WahidinSudirohusodo Hospital-LabuangBaji Hospital \\ Makassar, Indonesia
}

\begin{abstract}
Acute appendicitis is inflammation of the vermiform appendix due to lumen obstruction followed by bacterial infection. Acute appendicitis is classified into two types of disease, namely complicated and uncomplicated. Acute inflammation of the appendix requires immediate surgical action to prevent complications; therefore, a further laboratory test is required. This study was retrospective research which analyzed several hematologic parameters (WBC, Neutrophils, NLR, RDW, PLTMPV, PDW) and serum bilirubin levels. Data were statistically analyzed using Independent-t and Mann-Whitney test. Univariate logistic regression test was used to evaluate the correlation of hematologic parameters and significant serum bilirubin levels with the diagnosis of complicated and uncomplicated appendicitis. The cut-off value and diagnosis value were measured using Receiver Operating Characteristic (ROC) curve analysis. This study involved 173 subjects categorized into 67 complicated and 106 uncomplicated acute appendicitis patients. Whole blood count and neutrophil counts were significantly higher in complicated acute appendicitis ( $p<0.05$ ). Similarly, NLR and PLT were significantly higher in complicated acute appendicitis ( $p<0.001$ ), $p>0.05$ was obtained in RDW-CV, MPV and PDW values. The higher serum bilirubin levels were reported in patients with complicated acute appendicitis compared to uncomplicated acute appendicitis ( $p<0.001$ ). Logistic regression test results showed significant PLT parameters with $p<0.001$, while there was no significance of hematologic parameters such as WBC, neutrophil, NLR, RDW-CV, MPV, PDW and bilirubin levels. The area under curve results on the ROC curve showed $74.4 \%$ PLT with sensitivity and specificity of $97.17 \%$ and $40.29 \%$, respectively. From the analysis of hematologic parameters and measurement of serum bilirubin levels, only the PLT parameter can be used as one of the parameters for the diagnosis of complicated appendicitis with high sensitivity but low specificity. It was recommended to perform prospective studies with more subjects.
\end{abstract}

Keywords: Acute appendicitis, hematologic parameter, serum bilirubin

\section{INTRODUCTION}

Acute appendicitis is inflammation of the vermiform appendix due to lumen obstruction followed by bacterial infection. Acute appendicitis can be classified into two groups, namely complicated and uncomplicated. Acute complicated appendicitisis characterized by perforation, abscesses, gangrene, and peritonitis. The incidence of acute appendicitis in America is $1.1 / 1000$ population/year. It was reported that there were approximately 95 cases per 1000 population and 10 million cases every year in Indonesia. Acute appendicitis is an acute condition of the abdomen that is found in almost all hospitals in Indonesia. The highest incidence is found in the second and third decade of age and is 1.3-1.6 times more frequent in males than females. Acute inflammation of the appendix requires immediate surgical action to prevent complications that are generally dangerous; therefore, further laboratorytests are required to support the quick establishment of a diagnosis. ${ }^{1,2}$

The diagnosis of acute appendicitis remains a great challenge and controversial debate because the signs and symptoms that arise are similar to those of other abdominal diseases. Clinical diagnosis is commonly difficult even for experienced surgeons, as evidenced by high false explorative rates, which usually reach $20 \%$ to $30 \%$. Delayed diagnosis of acute appendicitis can cause several complications such as perforation, abscesses, sepsis and intestinal obstruction. Despite the increased use of 
Ultrasonography (USG), Computer Tomography $(\mathrm{CT})$, and diagnostic laparoscopy, the misdiagnosis of appendicitis tends to remain the same (15.3\%). This imaging modality is not enough to help prompt and precise diagnosis of acute appendicitis. ${ }^{3,4}$

The diagnosis of acute appendicitis is based on clinical symptoms and laboratory test results. A need for emergency surgery is determined based on diagnostic scores, such as the Kalesar and Alvarado score which combines clinical symptoms with laboratory results. Examination using USG is one of the attempts to improve the accuracy of diagnosis. ${ }^{1,2}$

Several recent studies have examined various parameters such as C-reactive protein, lymphocyte/leukocyte ratio, procalcitonin, fibrinogen, alpha 2-macroglobulin, alpha 1 -antitrypsin and D-Lactate for the diagnosis of acute appendicitis, but none was generally accepted. Simple, quick, widely applicable, and inexpensive laboratory test methods are needed to enable early detection of appendicitis before complications occur and reduce the number of negative appendectomy events. ${ }^{4}$

Hematological parameters have long been used as an indicator of inflammation and infection. Hematological examination is a routine, simple, and in expensive initial preliminary laboratory test. Some studies suggested that hematological parameters such as Mean Platelet Volume (MPV), Platelet Distribution Width (PDW), White blood cell (WBC), Neutrophil, and Neutrophil Lymphocyte Ratio (NLR) were proven to have diagnostic values in complicated appendicitis (perforation) ${ }^{3-5}$

White blood cells, such as neutrophils, are indicators of early inflammation in acute appendicitis. White blood cells are not specific markers and generally increases in patients with inflammatory conditions due to other causes. Red cell Distribution Width (RDW) is the measurement of size variability of red blood cells that was suggested by previous studies to associated with acute inflammation including acute appendicitis. ${ }^{6-8}$

Some studies correlated bilirubin levels with appendicitis, presumably be due to the spread of bacteria or toxins through the portal vein from the gastrointestinal tract to the liver. Research on hyperbilirubinemia as a predictor of perforated appendicitis has been performed by Chaudhary and serum bilirubin levels were suggested to be a potentially important adjunct in predicting the presence of perforated appendicitis. ${ }^{9-11}$

A study by Sevinç on simple laboratory parameters in appendicitis cases found that leukocyte counts, bilirubin levels, and NLR were significantly correlated with acute appendicitis. In addition, research by Ulukent on $C B C$ parameters suggested that leukocytes and NLR are better markers of inflammation of acute appendicitis. ${ }^{12,13}$

Based on the description above, the researcher examined the hematologic parameters (WBC, Neutrophil, NLR, RDW-CV, PLT, MPV, PDW) and total serum bilirubin as a parameter for diagnosis of complicated acute appendicitis.

\section{METHODS}

This research was a retrospective study using data of medical records of patients with a final diagnosis of acute appendicitis who had undergone appendectomy between January 2016 and December 2018 at the Medical Record Installation of Dr. Wahidin Sudirohusodo Hospital.

The study population was all patients with a final diagnosis of acute appendicitis and had undergone an appendectomy, who were treated in the Surgical Department of Dr. Wahidin Sudirohusodo Hospital, Makassar. The study sample is all accessible populations with complete data on hematologic parameters and serum bilirubin levels at Dr. Wahidin Sudirohusodo Hospital, Makassar in the period of January 2016-December 2018. The inclusion criteria were patients with a final diagnosis of acute appendicitis and had undergone appendectomy. Exclusion criteria were patients with incomplete medical record data. Hematologic parameters used in this study were leukocyte counts (WBC), neutrophil counts, RDW, NLR, platelet counts, Mean platelet volume, PDW obtained from routine blood tests in the laboratory using a hematology analyzer (Sysmex XS - 8001), while serum bilirubin was the total serum bilirubin levels measured based on blood chemistry tests using ABX Pentra 400.

Data were analyzed using SPSS 22 with the independent $t$-test for normally distributed data and the Mann-Whitney test for normally distributed data with a significant value of 0.05 . The univariate logistic regression test was used to determine the relationship between the diagnosis of complicated acute appendicitis and hematologic parameters. Multivariate logistic regression analysis was then performed after the parameters were stated as significant $(p<0.01)$ in the univariate logistic regression test. The cut-off value and diagnosis value of hematologic parameters in the prediction of acute appendicitis were measured using ROC curve analysis. 
This research was approved by the Health Research Ethics Committee of the Faculty of Medicine, Hasanuddin University/Central General Hospital Dr. Wahidin Sudirohusodo Makassar and Hasanuddin University Hospital Makassar with number 9796/UN4.6.8/PL.00.00/2019.

\section{RESULTS AND DISCUSSION}

The study was conducted on 173 patients with a final diagnosis of acute appendicitis who had undergone an appendectomy. Of 173 patients, 67 were found with complications and 106 without complications. The proportion of male subjects (64.16\%) was higher than that of females (35.84\%). Acute appendicitis was most frequently found in the group of younger adolescents age 18-25 years as many as 64 people (36.99\%) followed by childhood groups as many as 26 people (15.03\%) and most rarely found in toddlers (1.7\%). 173 patients with acute appendicitis were further divided into two groups based on their complications consisting of 67 (38.73\%) patients with complicated acute appendicitis and 106 (61.27\%) patients with uncomplicated appendicitis patients (Table 1 ).
After analyzed using the Kolmogorov-Smirnov test, $p<0.001$ was obtained, suggesting abnormal distribution. Therefore, the Mann-Whitney test was used. Table 2 shows a significantly higher WBC counts in complicated (16.44) compared to uncomplicated acute appendicitis (13.77) with $p=0.05$, as well as neutrophils $(p<0.05)$. Neutrophil lymphocyte ratio was found to be more highly significant in complicated appendicitis (11.48) compared to non-complicated (8.16) ( $p$ <0.001). Similarly, PLT was found to be more highly significant in complicated appendicitis (378.33) compared to uncomplicated appendicitis (266.85) ( $p$ <0.001). However, there was no significance of RDW-CV, MPV and PDW results in uncomplicated appendicitis ( $p>0.05$ ).

Of 173 acute appendicitis patients, only 21 patients had bilirubin data, consisting of 13 complicated and 8 uncomplicated appendicitis patients. After analysis using the Shapiro-Wilk test, p> 0.05 was obtained, suggesting a normal data distribution. Independent $\mathrm{t}$-test showed a higher significant difference in serum bilirubin levels in patients with acute complicated appendicitis (0.97) compared to uncomplicated appendicitis $(0.52)$ with

Table 1. General characteristics of research subjects

\begin{tabular}{|c|c|c|c|}
\hline Variable & n (\%) & Mean \pm SD & Min-Max \\
\hline \multicolumn{4}{|l|}{ Gender } \\
\hline Male & $111(64.16)$ & & \\
\hline Female & $62(35.84)$ & & \\
\hline \multicolumn{4}{|l|}{ Age group (year) } \\
\hline $0-5$ & $3(1.7)$ & & \\
\hline $6-11$ & $15(8.67)$ & & \\
\hline $12-17$ & $26(15.03)$ & & \\
\hline $18-25$ & $64(36.99)$ & & \\
\hline $26-35$ & $19(10.98)$ & & \\
\hline $36-45$ & $18(10.40)$ & & \\
\hline $46-56$ & $13(7.51)$ & & \\
\hline $56-65$ & $11(6.36)$ & & \\
\hline$>65$ & $4(2.31)$ & & \\
\hline \multicolumn{4}{|c|}{ Acute appendicitis $(n=173)$} \\
\hline Complicated & $67(38.73)$ & & \\
\hline Uncomplicated & $106(61.27)$ & & \\
\hline \multicolumn{4}{|l|}{ Parameter } \\
\hline WBC & $173(100)$ & $14.8 \pm 5.95$ & $3.3-36.8$ \\
\hline Neutrophils & $173(100)$ & $77.69 \pm 13.5$ & $30.4-96.2$ \\
\hline NLR & $173(100)$ & $9.44 \pm 7.29$ & $0.51-48.1$ \\
\hline RDW-CV & $173(100)$ & $12.87 \pm 1.37$ & $9.9-19$ \\
\hline PLT & $173(100)$ & $309,63 \pm 116$ & $150-182$ \\
\hline MPV & $173(100)$ & $9.23 \pm 1.27$ & $6-12.9$ \\
\hline PDW & $173(100)$ & $11.68 \pm 2.26$ & $7.4-19.8$ \\
\hline Bilirubin & $21(12.14)$ & $0.8 \pm 0.3$ & $0.32-0.38$ \\
\hline
\end{tabular}


p <0.001, suggesting a significant association between increased serum bilirubin levels and complicated appendicitis (Table 3).

Logistic regression test results showed significant PLT parameters ( $p<0.001$ ) but insignificant WBC, neutrophil, NLR, RDW-CV, MPV, PDW and bilirubin levels (Table 4).

The AUC score of the ROC curve showed $>60 \%$ PLT parameter (Figure 1). Table 5 is a proposed cut-off value that can be used in the diagnosis of acute appendicitis. This study found that acute appendicitis was more common in males than females. The results of this study were in line with research by Tanrikulu et al.,Yilmas et al., and study by Toktas and Aslan., ${ }^{3,4}$ These results were in accordance with epidemiological data of acute appendicitis which showed a higher incidence of the disease in males than females with a ratio of $3: 2 .^{3,4}$

Thrombocytosis frequently occurs in infections and inflammation. The role of platelets in the inflammatory process has been investigated and the relationship between their activation and inflammatory diseases has been widely reported. Inflammation marked by a remarkable increase of inflammatory cytokines activates megakaryocytes in the bone marrow and increases the release of young platelets into the peripheral blood circulation. Platelets were significantly higher in complicated compared to uncomplicated acute appendicitis $(p<0.001)$, suggesting a similar result to study by

Table 2. Analysis of hematologic parameters and serum bilirubin levels in complicated and uncomplicated acute appendicitis

\begin{tabular}{lccc}
\hline & \multicolumn{2}{c}{ Acute Appendicitis (n=173) } & \multirow{2}{*}{$\mathbf{p}^{*}$} \\
\cline { 2 - 3 } & $\begin{array}{c}\text { Complicated }(\mathbf{n}=\mathbf{6 7}) \\
\text { Mean } \pm \text { SD }\end{array}$ & $\begin{array}{c}\text { Uncomplicated }(\mathbf{n = 1 0 6}) \\
\text { Mean } \pm \text { SD }\end{array}$ \\
\hline WBC & $16.44 \pm 6.68$ & $13.77 \pm 5.22$ & 0.05 \\
Neutrophils & $81.53 \pm 7.87$ & $75.26 \pm 13.91$ & 0.006 \\
NLR & $11.48 \pm 7.35$ & $8.16 \pm 6.99$ & $<0.001$ \\
RDW-CV & $13.1 \pm 1.51$ & $12.72 \pm 1.26$ & 0.039 \\
PLT & $378,33 \pm 141,17$ & $266,85 \pm 69.01$ & $<0.001$ \\
MPV & $9.3 \pm 1.12$ & $9.18 \pm 1.36$ & 0.14 \\
PDW & $11.37 \pm 2.12$ & $11.88 \pm 2.34$ & 0.18 \\
\hline
\end{tabular}

* Mann-Whitney test

Table 3. Analysis of serum bilirubin levels in complicated and uncomplicated acute appendicitis

\begin{tabular}{|c|c|c|c|c|}
\hline \multirow[b]{2}{*}{ Parameter } & \multicolumn{3}{|c|}{ Acute Appendicitis $(n=21)$} & \multirow[b]{2}{*}{$\mathbf{P}^{*}$} \\
\hline & \multicolumn{2}{|l|}{$\begin{array}{l}\text { Complicated }(n=13) \\
\text { Mean } \pm \text { SD }\end{array}$} & $\begin{array}{c}\text { Uncomplicated }(n=8) \\
\text { Mean } \pm \text { SD }\end{array}$ & \\
\hline Bilirubin & $0.97 \pm 0.23$ & & $0.52 \pm 0.14$ & $<0.001$ \\
\hline \multicolumn{5}{|l|}{ * Independent T-test } \\
\hline Parameter & $\begin{array}{c}\text { Univariate } \\
\text { p }\end{array}$ & OR & $\begin{array}{c}\text { Multivariate } \\
\text { 95\%CI (min-max) }\end{array}$ & $\mathbf{p}$ \\
\hline WBC & 0.005 & - & - & - \\
\hline Neutrophil & 0.002 & - & - & - \\
\hline NLR & 0.006 & - & - & - \\
\hline RDW-CV & 0.085 & - & - & - \\
\hline PLT & $<0.001$ & 1.013 & $1.008-1.018$ & $<0.001$ \\
\hline MPV & 0.560 & - & - & - \\
\hline PDW & 0.152 & - & - & - \\
\hline Bilirubin & 0.194 & - & - & - \\
\hline
\end{tabular}

* Logistic Regression 


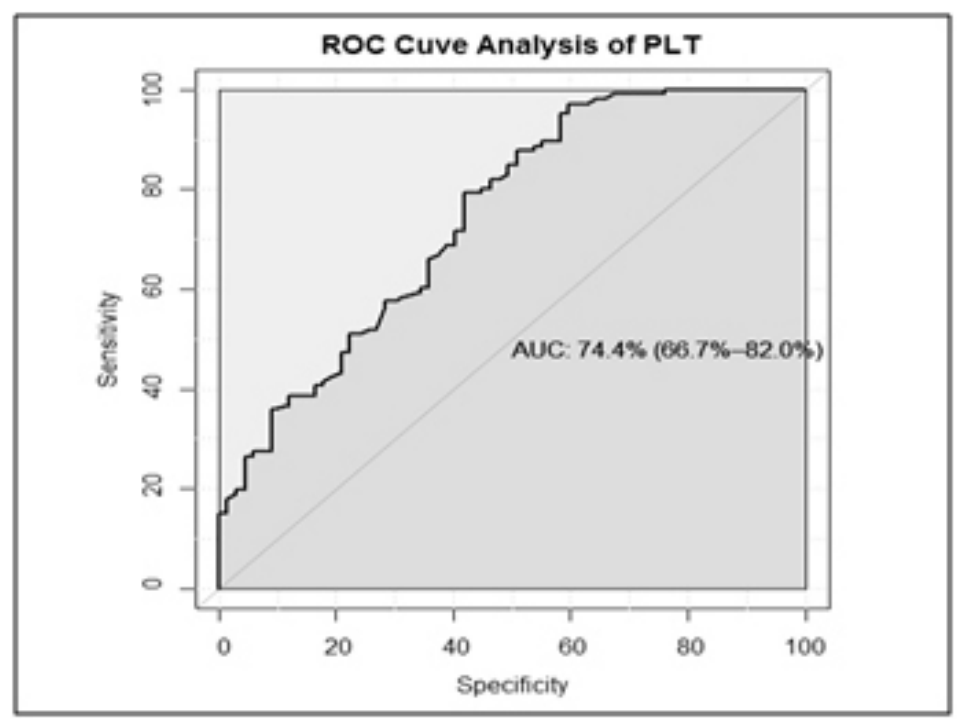

Figure 1. ROC curve of PLT

Table 5. The cut-off value of PLT to predict complicated acute appendicitis

\begin{tabular}{cccccccc}
\hline Parameter & Cut-off & Sensitivity (\%) & Specificity (\%) & PPV (\%) & NPV (\%) & AUC (\%) & Accuracy (\%) \\
\hline PLT & 388,00 & 97.17 & 40.29 & 72.03 & 90.00 & 74.4 & 75.15 \\
\hline
\end{tabular}

PPV: Positive Predictive Value; NPV: Negative Predictive Value; AUC: Area Under the Curve

Aydogan and Sevinc, while research by Boshnak obtained the contradictory results that there was no significant relationship between complicated and uncomplicated acute appendicitis. ${ }^{6,12,14}$ Based on analysis using log regression test, PLT can be used as a parameter to diagnose acute appendicitis with a cut-off value of $388000 / \mu \mathrm{L}$, with good sensitivity (97.17\%) but low specificity (40.29\%), suggesting that these parameters cannot be used as a single parameter to diagnose acute appendicitis. ${ }^{6,14}$

In appendicitis, mucosal ulceration that occurs due to inflammation can facilitate the transfer of bacteria from the appendix to the portal vein and subsequently to the liver. The most commonly found bacteria in infection is Gram-negative Escherichia coli which interferes with hepatocyte microcirculation leading to induced damage to liver cells and interferes with bile excretion, in addition to intravascular hemolysis. These mechanisms cause high bilirubin levels in the blood circulation. There were significant differences of bilirubin levels in complicated and uncomplicated acute appendicitis. The value of serum bilirubin in patients with complicated acute appendicitis was higher than uncomplicated $(p<0.001)$. These results were in line with research by Chaudhary, despite the insignificant result of log regression correlation test due to the limited number of samples. ${ }^{9,10,15}$

\section{CONCLUSIONS AND SUGGESTIONS}

From the analysis of hematologic parameters and serum bilirubin levels, only PLT parameters can be used as a parameter for the diagnosis of complicated appendicitis with high sensitivity but have low specificity. Further prospective studies with the use of more samples were highly recommended.

\section{REFERENCES}

1. Abdurachman SA. Apendisitis akut.Dalam: Ilmu penyakit dalam. Jilid II, Jakarta, Balai Penerbit FKUI, 2005: 177-82.

2. Sjamsuhidajat $\mathrm{R}$, Wim de Jong. Apendiksvermiformis. Dalam: Buku ajar ilmu bedah. Ed Revisi, Jakarta,EGC, 2008; 865.

3. Toktas O, Asian M. Mean platelet volume, red cell distribution width, neutrophil to lymphocyte ratio and platelet to lymphocyte ratio in the diagnosis of acute appendicitis. Eastern Journal of Medicine, 2017; 22(1): 5-9.

4. Tanrikulu CS, Tarinkulu Y, Sabuncuoglu MZ, Karamercan MA, Akkapulu N, et al. Mean platelet volume and red cell distribution width as a diagnostic marker in acute appendicitis. Iran Red Crescent Med Journal, 2014; 16(5): e10211.

5. Atas H, Kiliç MÖ, Terzioğlu SG, Saylam B. Role of hematological parameters in prediction of complicated appendicitis. Wien Klin Wochenschr. The Central Europian Journal, 2017; 129(9-10): 369-371. 
6. Noha Boshnak, Mohamed Boshnaq, Hatem Elgohary. Evaluation of platelet indices and red cell distribution width as new biomarkers for the diagnosis of acute appendicitis. Journal of Investigative Surgery, 2017; 31(2): 121-129.

7. Shogilev DJ, Duus N, Odom SR, Shapiro NI. Diagnosing appendicitis: Evidence-based review of the diagnostic approach in 2014. Western Journal of Emergency Medicine, 2015; 15(7): 859.

8. Narci H, Turk E, Karagulle E, Togan T, Karabulut K. The role of red cell distribution width in the diagnosis of acute appendicitis: a retrospective case-controlled study. World J Emerg Surg, 2013; 8(1): 46-52.

9. Khan Salamat. Evaluation of hyperbilirubinemia in acute inflammation of appendix: A prospective study of 45 cases. Kathmandu University Medical Journal, 2006; 4(3): 281-289.

10. Beltran MA, Mendez $P E$, Barrera RE, Contreras MA, Wilson CS, et al. Is hyperbilirubinaemia in appendicitis a better predictor of perforation than C-reactive protein? - a prospective study. Indian J Surg,
2009: 71: 265-272.

11. Chaudhary P, Kumar A, Saxena N, Biswal UC. Hyperbilirubinemia as a predictor of gangrenous/ perforated appendicitis: a prospective study. Annals of Gastroenterology, 2013; 26: 325-331.

12. Sevinç MM, Kınac1 E, Çakar E, Bayrak S, Özakay A, et al. Diagnostic value of basic laboratory parameters for simple and perforated acute appendicitis: An analysis of 3392 cases. Turkey. Ulus Travma Acil Cerrahi Derg, 2016; 22(2): 155-162.

13. Ulukent SC. All CBC parameters in diagnosis of acute appendicitis. Int J ClinExp Med, 2016; 9(6): 11871-11876.

14. Burcharth J, Pommergaard HC, Rosenberg J, Gögenur I. Hyperbilirubinemia as a predictor for appendiceal perforation: A systematic review. Scandinavian Journal of Surgery,2013; 102: 55-60.

15. Aydogan A, Akkucuk S, Arica S, Motor S, Karakus A, et al. The analysis of mean platelet volume and platelet distribution width levels in appendicitis. Indian J Surg, 2015;77: 495-500. 